University of Wollongong

Research Online

Faculty of Engineering and Information

Faculty of Engineering and Information

Sciences - Papers: Part B

Sciences

2017

Predicting Steel Tensile Responses and Fracture Using the

Phenomenological Ductile Shear Fracture Model

Kazeem K. Adewole

University of Ibadan

Lip H. Teh

University of Wollongong, Iteh@uow.edu.au

Follow this and additional works at: https://ro.uow.edu.au/eispapers1

Part of the Engineering Commons, and the Science and Technology Studies Commons

Research Online is the open access institutional repository for the University of Wollongong. For further information contact the UOW Library: research-pubs@uow.edu.au 


\title{
Predicting Steel Tensile Responses and Fracture Using the Phenomenological Ductile Shear Fracture Model
}

\author{
Abstract \\ In the literature, all the micromechanical fracture models used for predicting structural steel tensile \\ responses and fracture are based on the ductile fracture mechanism that uses the Lode angle parameter \\ to simulate shear fracture under low-stress triaxiality. Using the phenomenological shear fracture model \\ that uses the shear stress ratio rather than the Lode angle parameter, this technical note presents the \\ finite element predictions of the responses of $\mathbf{S 6 9 0}$ steel solid and perforated coupons under tension and \\ of the fractures of TRIP (transformation-induced plasticity) 690 steel specimens under pure shear and \\ combined shear and tension. The calibrated phenomenological shear fracture model parameters are \\ obtained through a phenomenological curve-fitting process that does not involve costly laboratory tests. \\ This technical note demonstrates that the phenomenological shear fracture model can accurately predict \\ the responses and fracture of structural steels under tension, pure shear, and combined shear and \\ tension. \\ Disciplines \\ Engineering | Science and Technology Studies

\section{Publication Details} \\ Adewole, K. K. \& Teh, L. H. (2017). Predicting Steel Tensile Responses and Fracture Using the \\ Phenomenological Ductile Shear Fracture Model. Journal of Materials in Civil Engineering, 29 (12), \\ 06017019-1-06017019-6.
}


Predicting steel tensile responses and fracture using the phenomenological ductile shear

\section{ABSTRACT} fracture, void growth mechanism combined shear and tension.

\section{fracture model}

\author{
Kazeem K. Adewole ${ }^{1}$ and Lip H. Teh ${ }^{2}$ M.ASCE
}

In the literature, all the micromechanical fracture models employed for predicting structural steel tensile responses and fracture are based on the ductile fracture mechanism which employed the Lode angle parameter to simulate shear fracture under low stress triaxiality. Using the phenomenological shear fracture model that employs the shear stress ratio rather than the Lode angle parameter, this technical note presents the finite element predictions of the responses of S690 steel solid and perforated coupons under tension, and of the fractures of TRIP (Transformation Induced Plasticity) 690 steel specimens under pure shear and under combined shear and tension. The calibrated phenomenological shear fracture model parameters are obtained through phenomenological curve fitting process that does not involve costly laboratory tests. This technical note demonstrates that the phenomenological shear fracture model can accurately predict the responses and fracture of structural steels under tension, pure shear and

\footnotetext{
${ }^{1}$ Lecturer, Civil Engineering Department, University of Ibadan, Ibadan, Nigeria, E-mail:kkadewole@yahoo.com

${ }^{2}$ Associate Professor, School of Civil, Mining and Environmental Engineering, Univ. of Wollongong, Wollongong, NSW 2500, Australia E-mail: 1teh@uow.edu.au
} 


\section{Introduction}

Ductile materials exhibit two types of fracture: "ductile shear fracture" and "ductile tensile fracture" (Björklund and Nilsson 2014). Either mode or a combination of both may take place in structural steel (Hooputra et al. 2004, Björklund et al. 2013). Fracture initiation in the shear mode occurs under intense shear stresses resulting either from extensive slip on the activated slip planes and/or microcracking without any void nucleation, or from void nucleation in the slip bands (French and Weinrich 1979). In any case, the shear mode is less pressure-dependent than the tensile mode (Björklund et al. 2013).

In the tensile mode, fracture initiation is always associated with void nucleation under predominantly tensile stresses at high stress triaxiality (Björklund et al. 2013). The growth and coalescence of nucleated voids in this mode occur under varying stress conditions with varying fracture mechanisms as the ductile fracture propagates (Danas and Castañeda 2014). The initial growth and coalescence, which are associated with inter-void ligaments necking, occur under high stress triaxiality and pure hydrostatic stress. The growth and coalescence then takes place under intermediate and subsequently low stress triaxiality. Under the intermediate stress triaxiality, a transition from the predominantly tensile stresses-based void growth mechanism to the predominantly shear stresses-based void shearing mechanism occurs (Danas and Castañeda 2012).

The Gurson-Tvergaard-Needleman model or Gurson-like models (Cockroft and Latham 1968, Wilkins et al. 1980, Gologanu et al. 1993) and the Rice and Tracey's void growth model or its variants (Rice and Tracey 1969, Kanvinde \& Deierlein 2006, Jia and Kuwamura 2013, Kiran and Khandelwal 2013) have been employed to simulate the void nucleation, growth, and coalescence fracture mechanism. However, these models generally fail to predict predominantly 
shear fracture under low and negative stress triaxiality (Danas and Castañe 2012, Wen and Mahmoud 2015). A parameter that improves the simulation in the later stage of the ductile fracture mode under low stress triaxiality, called the Lode angle, has been used to simulate the void shearing effect (Xue 2008, Nahshon and Hutchinson 2008, Bai and Wierzbicki 2008, Danas and Castañe 2012, Cheng et al. 2015, Wen and Mahmoud 2015, Li et al. 2016). The Lode angle is used to distinguish the different shear stress states in three dimensions.

In any case, all the aforementioned models require a number of parameters (up to nine) that are to be calibrated from elaborate laboratory tests, with some requiring fractographic analysis. Costly laboratory tests are therefore required to obtain the calibrated parameters (Bernauer and Brocks 2002), which are not feasible for most design firms (Kiran and Khandelwal 2013).

An economical method for obtaining the required fracture parameters is the phenomenological curve fitting process. The phenomenological curve fitting process involves keeping some parameters constant while varying others during numerical simulations until the simulation results match the experimental results up to the displacement at fracture (Bernauer and Brocks 2002). The parameters at which the simulated displacement at fracture matches the experimental displacement are the set of critical/calibrated fracture parameters (Bernauer and Brocks 2002). This phenomenological procedure can be used without the need for any extensive laboratory tests other than the standard tension coupon test.

Since fracture of structural steel could be by either the shear or the tensile mode, or a combination of both, it is important to employ models that are capable of capturing the two modes (Björklund et al 2013). To the best of the authors' knowledge, the prediction of tensile responses of civil engineering structural steel using the phenomenological shear fracture model 
84 Equation (1) is satisfied when the equivalent plastic strain reaches the critical value $\varepsilon_{e q}^{* *}$ given by

that simulates ductile tensile fracture under high stress triaxiality and employs the shear stress ratio rather than the Lode angle parameter to simulate ductile shear fracture under low/negative triaxiality has not been published. All the published fracture models on structural steel that predict both ductile tensile fracture and ductile shear fracture employ the Lode angle parameter for ductile shear fracture prediction.

The phenomenological shear damage and fracture model (Hooputra et al. 2004) presented in this technical note simulates the ductile tensile fracture and the ductile shear fracture involving void nucleation, void shearing and elongation, inter-voids shear localisation and void coalescence under intense shear stresses (low and negative stress triaxiality). It is employed in the present work to obtain the calibrated model parameters for S690 steel. The simulations of fractures of TRIP (Transformation Induced Plasticity) 690 steel specimens under pure shear and under combined shear and tension are also presented.

\section{Phenomenological shear damage and fracture model/criterion}

The phenomenological shear damage and fracture model employs the equivalent plastic strain as the failure parameter (Hooputra et al. 2004). Shear damage initiation begins when the shear damage initiation criterion, which is a function of the equivalent plastic strain $\varepsilon_{e q}$, is satisfied, as shown in the following equation

$$
\int_{0}^{\varepsilon_{e q}^{* *}} \frac{d \varepsilon_{e q}}{\varepsilon_{e q}^{* *}(\eta)}=1
$$




$$
\varepsilon_{e q}^{* *}=\frac{\varepsilon_{S}^{+} \sinh \left[f\left(\theta_{s}^{+}-\theta_{s}^{-}\right)\right]+\varepsilon_{S}^{-} \sinh \left[f\left(\theta_{s}^{+}-\theta_{s}^{-}\right)\right]}{\sinh \left[f\left(\theta_{s}^{+}-\theta_{s}^{-}\right)\right.}
$$

$$
\theta_{s}=\frac{\left(1-k_{s} \eta\right) \sigma_{e q}}{\tau_{\max }}
$$

The parameters $\varepsilon_{S}^{+}$and $\varepsilon_{S}^{-}$are the equivalent plastic strains at shear damage initiation for equibiaxial tensile and compressive deformations, respectively, while $f$ is an orientation dependent parameter and $k_{s}$ is a material parameter. The first three parameters, which depend on the material type and the strain rate, "must" be determined experimentally. The variable $\eta$ is the stress triaxiality. $\theta_{s}^{+}$and $\theta_{s}^{-}$are the shear stress ratios for equibiaxial tension (at $\eta=\eta^{+}$) and compression (at $\eta=\eta^{-}$), respectively, which depend on the maximum shear stress $\tau_{\max }$, the equivalent stress $\sigma_{e q}$ and the stress triaxility $\eta$, as shown in equation 3 .

Shear damage initiation is associated with the progressive degradation of the elasticity or material stiffness which commences at the moment of the strain softening of the material at the point of the ultimate strength/stress (Henning 2012). Shear damage initiation is followed by damage evolution that is specified in terms of the equivalent plastic displacement, $U^{p l}$. Material failure typified by the complete loss of load-carrying capacity takes place in elements with completely degraded stiffness, which occurs when the equivalent plastic displacement $U^{p l}$

101 reaches the critical value, the equivalent plastic displacement at failure $U_{f}^{p l}$. The equivalent 102 plastic displacement at failure $U_{f}^{p l}$ is specified as zero for instantaneous failure, and greater than 103 zero (up to unity) for progressive failure. When the material fails, the damage variable $d$ reaches 104 its maximum value $d_{\max }$, and elements with completely degraded stiffness are either retained or 
removed from the mesh. The default value of $d_{\max }$ is 1.0 , but can be specified by the user as 0.99 (ABAQUS 2014).

Calibration of S690 structural steel model parameters using phenomenological curve fitting

Moze et al. (2007) conducted the tension coupon tests on S690 solid and perforated structural steel coupons, depicted in Figures 1(a) and 1(b), respectively. The hole in the perforated tension coupon H04 had a diameter of $10 \mathrm{~mm}$, which was the same as the coupon thickness. The elongation of each coupon was measured by Moze et al. (2007) over a gauge length of $280 \mathrm{~mm}$.

The coupon models in Figures 1(c) and 1(d) were meshed with $1 \mathrm{~mm} \times 1 \mathrm{~mm} \times 1 \mathrm{~mm}$ C3D8R element that had been established through mesh convergence studies to be the appropriate element size. C3D8R elements are 8-node hexahedral linear brick reduced integration elements with hourglass control. Non-linear quasi-static analyses were conducted using the explicit solver (ABAQUS 2014) at the default step time of one second to ensure that the kinetic energy is far less than $5 \%$ of the total energy. The true stress-strain curves were calculated from the published experimental force-displacement (Moze et al. 2007). The elastic modulus is assumed to be 200 GPa, with a Poisson's ratio of 0.3 . The inelastic responses of the coupons were modelled with the isotropic hardening rule and the von Mises yield criterion.

121 The experimental displacement at fracture of the solid coupon was not provided by Moze et al 122 (2007), so the calibration was conducted on the perforated coupon H04 instead, of which the 123 experimental displacement at fracture was $6.6 \mathrm{~mm}$. The ultimate test load was $811 \mathrm{kN}$.

124 The phenomenological curve fitting process was conducted on the perforated coupon model with

125 the material parameter $k_{s}$ and the equivalent plastic displacement at failure $U_{f}^{p l}$ being kept 
constant at 0.1 (Hooputra et al. 2004), while the equivalent plastic strain at shear fracture, shear stress ratio and strain rate were varied, as shown in Table 1. Parameter combination A was the experimentally calibrated values employed by Hooputra et al. (2004) for the simulation of ductile fracture in aluminum alloy EN-AW-7108 TC. Parameter combinations B to E are linear multiples $(2.5,3.0,3.5$, and 4.0) of the parameter combination A.

As shown in Table 2, parameter combination $\mathrm{D}$ resulted in the closest estimate of the experimental displacement at fracture obtained by Moze et al (2007) for the perforated specimen H04. The experimental load-displacement curve can be compared to that obtained using parameter combination D in Figure 2.

In order to verify that the material parameter $k_{\mathrm{s}}$ has little if any significance in the S690 steel tensile responses predicted using the phenomenological fracture model, eleven simulations were conducted for the specimen H04 using the same parameters as the parameter combination D except for the material parameter, which was varied from 0 to 10 at a step of 1 . It was found that all eleven simulations returned the same results as the parameter combination $\mathrm{D}$, which had a material parameter $k_{\mathrm{s}}$ equal to 0.1 .

\section{FE predictions of the ultimate loads and displacements at fracture of perforated coupons}

In addition to the solid and perforated coupons H04 discussed in the preceding section, Moze et al. (2007) tested perforated tension coupons with hole diameters of $5 \mathrm{~mm}, 13 \mathrm{~mm}, 18 \mathrm{~mm}, 22$ mm, $26 \mathrm{~mm}, 30 \mathrm{~mm}, 40 \mathrm{~mm}$ and $50 \mathrm{~mm}$, designated as specimens H03, H06, H07, H08, H10, H12, H15 and H16, respectively. The load-displacement curves up to the displacement at fracture predicted using the parameter combination D are shown in Figure 3. The ultimate loads and displacements at fracture obtained numerically by the authors and experimentally by Moze 
et al. (2007) are shown in Table 3. The variable $R_{\mathrm{EP}}$ represents the ratio of the experimental values to the predicted values.

Both the experimental tests (Moze et al. 2007) and the present simulations found that the perforated coupon with a 5-mm hole, H03, exhibited the largest displacements at fracture, being $9.0 \mathrm{~mm}$ and $10.7 \mathrm{~mm}$, respectively. Incidentally, the difference between the experimental and the simulation results is the greatest for this coupon. In any case, the consistently accurate predictions of the tensile responses of the solid and perforated coupons, as evident in Table 3, demonstrate that the phenomenological shear damage and fracture model presented in this technical note is feasible and reliable.

\section{Simulations of ductile fracture under pure shear and under combined shear and tension}

In order to establish the ability of the present phenomenological shear damage and fracture model to predict fractures under pure shear and under combined shear and tension, the pure shear and the combined shear and tension loading tests of TRIP 690 steel specimens by Bai and Wierzbicki (2010) were simulated. The fracture simulation were conducted using a true yield stress of $445 \mathrm{MPa}$, a true tensile strength of $920 \mathrm{MPa}$, a true yield strain of 0.02 and a true ultimate strain of 0.26 reported $\mathrm{Li}$ et al. (2010). An equivalent fracture strain of 1.1044, a shear

164 stress ratio of 40 , a strain rate of $0.00040 \mathrm{~s}^{-1}$, a material parameter of 0.1 and an equivalent 165 plastic displacement at failure of 0.1 were obtained through the phenomenological curve fitting 166 process. The models of the pure shear specimen and of the combined shear and tension specimen are shown in Figures 4(a) and 4(b), respectively. The gauge sections of both specimens were meshed 
with $1 \mathrm{~mm} \times 0.25 \mathrm{mmx} 0.25 \mathrm{~mm}$ elements while the other sections were meshed with $1-\mathrm{mm}$ cube

171 elements. The loading pins were modeled as 3D analytical rigid cylindrical shells with the reference points at their base centers. The general contact (explicit) algorithm with the tangential behaviour penalty frictional interaction and a friction coefficient of 0.15 were employed to model

174 the contact between the loading pins and the specimens. The top pins were fixed and the bottom 175 pins were subjected to vertical downward displacements until the specimens fractured.

176 The predicted fracture processes of the specimens are shown in Figures 5 and 6 respectively. The 177 failure of the specimen subjected to pure shear began with the initiation of a vertical fracture 178 approximately parallel to the loading direction at the middle of the bottom end of the butterfly 179 gauge section (Figure 5(a)), where the shear damage initiation criterion designated as SHRCRT 180 (ABAQUS 2014) first reached its critical value of 1 . The vertical fracture propagated upwards and the model fractured completely as shown in Figure 5(b). The failure of the specimen subjected to combined shear and tension began with the initiation of a fracture inclined to the loading direction at the top end of the strip gauge section, as shown in Figure 6(a). The initiated slanted fracture propagated downwards and the model fractured completely as shown in Figure 6(b).

Bao and Wierzbicki, $(2004,2010)$ were unable to capture the exact location of the fracture initiation and the fracture propagation. Consequently, the predicted fracture processes of the specimens subjected to pure shear and to combined shear and tension could not be validated against their experimental results. However, it can be seen from the good agreements between the experimental fracture shapes (Bao and Wierzbicki, 2010) and the simulated ones shown in

191 Figure 7 that the present phenomenological shear damage and fracture model is capable of 192 modelling fractures under pure shear and under combined shear and tension. 
194 The predictions of structural steel tensile responses and fractures under tension, pure shear and 195 combined shear and tension using the phenomenological shear fracture model that simulates 196 ductile shear fracture based on the shear stress ratio (rather than the Lode angle parameter) has 197 been presented. This technical note has covered the predictions of tensile responses of S690 steel 198 solid coupons and perforated coupons having different hole diameters. It has also simulated the 199 fractures of TRIP 690 steel specimens under pure shear and under combined shear and tension. 200 The calibrated phenomenological shear damage and fracture model parameters, being the 201 equivalent fracture strain, the shear stress ratio, the strain rate, the equivalent displacement at 202 fracture and the material parameter were obtained through phenomenological curve fitting 203 process. It has been found that the material parameter $k_{\mathrm{s}}$ has no noticeable effect on the shear 204 damage and fracture, and the tensile responses (ultimate load and displacement at fracture) of 205 structural steels

206 This technical note has demonstrated that the phenomenological shear fracture model can be 207 employed in the design office for the predictions of ultimate loads and displacements at fracture 208 required for the design of resilient or fracture-resistant steel structures, and for simulating the 209 complete fracture process in structural steel. The phenomenological shear damage and fracture model parameters can be obtained through phenomenological curve fitting process that does not 211 require costly laboratory tests. 
213 Table 1. Parameter combinations for S690 steel

\begin{tabular}{lccccc}
\hline Parameter & Equivalent & Shear & Strain & Material & Equivalent Plastic \\
Combinations & Fracture Strain & Stress & Rate & Parameter & Displacement at \\
& $\varepsilon_{e q}^{* *}$ & Ratio $\theta_{s}^{+}$ & $\left(\mathrm{s}^{-1}\right)$ & $k_{s}$ & Failure \\
\hline A & 0.27610 & 10 & 0.00010 & 0.1 & 0.1 \\
B & 0.69025 & 25 & 0.00025 & 0.1 & 0.1 \\
C & 0.82830 & 30 & 0.00030 & 0.1 & 0.1 \\
D & & & & & 0.1 \\
E & 0.96635 & 35 & 0.00035 & 0.1 & 0.1 \\
\hline
\end{tabular}


215 Table 2. Ultimate loads and displacements at fracture of perforated specimen H04

\begin{tabular}{lcccc}
\hline Parameter & Predicted Load & Difference & Predicted Displacement & Difference \\
Combinations & $(\mathrm{kN})$ & $(\%)$ & at Fracture $(\mathrm{mm})$ & $(\%)$ \\
\hline A & 800 & 1.28 & 2.97 & 55.0 \\
B & 800 & 1.28 & 5.17 & 21.7 \\
C & 800 & 1.28 & 5.87 & 11.1 \\
D & 800 & 1.28 & & 0.04 \\
E & 800 & 1.28 & 6.59 & 11.5 \\
\hline
\end{tabular}


217 Table 3. Experimental and FE ultimate loads and displacements at fracture

Specimen Hole Size (mm) Ultimate Loads Displacement at Fracture

\begin{tabular}{|c|c|c|c|c|c|c|c|}
\hline & & $\begin{array}{l}\text { Test } \\
(\mathrm{kN})\end{array}$ & $\begin{array}{c}\text { FE } \\
(\mathrm{kN})\end{array}$ & $R_{\mathrm{EP}}$ & $\begin{array}{l}\text { Test } \\
(\mathrm{mm})\end{array}$ & $\begin{array}{c}\mathrm{FE} \\
(\mathrm{mm})\end{array}$ & $R_{\mathrm{EP}}$ \\
\hline H01 & 0 & 886 & 875 & 1.01 & 22.5 & 21.5 & 1.05 \\
\hline H03 & 5 & 861 & 860 & 1.00 & 9.0 & 10.7 & 0.84 \\
\hline H04 & 10 & 811 & 799 & 1.01 & 6.6 & 6.5 & 1.02 \\
\hline H06 & 13 & 789 & 782 & 1.01 & 7.0 & 6.9 & 1.01 \\
\hline H07 & 18 & 747 & 733 & 1.02 & 7.1 & 6.9 & 1.03 \\
\hline H08 & 22 & 716 & 702 & 1.02 & 7.1 & 7.3 & 0.97 \\
\hline H10 & 26 & 679 & 665 & 1.02 & 7.9 & 7.9 & 1.00 \\
\hline H12 & 30 & 641 & 627 & 1.02 & 8.0 & 7.9 & 1.01 \\
\hline H15 & 40 & 542 & 542 & 0.99 & 8.2 & 7.8 & 1.05 \\
\hline H16 & 50 & 456 & 454 & 1.00 & 8.4 & 9.2 & 0.91 \\
\hline
\end{tabular}


References:

ABAQUS (2014) ABAQUS Analysis User's Manual, Version 6.14, Dassault Systèmes, Providence RI.

Bao, Y. and Wierzbicki, T. (2004) "On fracture locus in the equivalent strain and stress triaxiality space.” Int. J. Mech. Sci.,46, 81-98

Bai, Y. and Wierzbicki, T. (2008) "A new model of metal plasticity and fracture with pressure and Lode dependence.” Int. J. Plasticity, 24, 1071-1096.

Bai, Y., Wierzbicki, T. (2010). "Application of extended Mohr-Coulomb criterion to ductile fracture."Int J Fract,161:1-20

Bernauer, G. and Brocks, W. (2002) "Micro-mechanical modelling of ductile damage and tearing-results of a European numerical round robin". Fatigue and Frac. of Eng. Mat. \& Struct. , 25(4), 363-384.

Björklund, O., Larsson, R. and Nilsson, L. (2013) "Failure of high strength steel sheets: Experiments and modeling." J. Mat. Proc. Tech., 213, 1103-1117.

Björklund, O. and Nilsson, L. (2014) "Failure characteristics of a dual-phase steel sheet." J. Mat. Proc. Tech., 214, 1190-1204.

Cheng, L., Monchiet, V., Morin, L., Saxcé, G. and Kondo, D. (2015) “An analytical Lode angle dependent damage model for ductile porous materials." Eng. Fract. Mech., 149, 119-133.

Danas, K. and Castañed, P. P. ( 2012) "Influence of the Lode parameter and the stress triaxiality on the failure of elasto-plastic porous materials.” Int. J. Solids and Struct., 49, 1325-1342.

French, I. E. and Weinrich, P. F. (1979) “The shear mode of ductile failure in mild steel." Mat. Sci. Eng., 39 (1), 43-46. 
Gologanu, M., Leblond, J. B. and Devaux, J. (1993) “Approximate models for ductile metals containing nonspherical voids - case of axisymmetrical prolate ellipsoidal cavities". J. Mech. Phys. Solids, 41 (11), 1723-1754.

Henning, L. (2012). Simulating Ductile Fracture in Steel using the Finite Element Method: Comparison of Two Models For Describing Local Instability due to Ductile Fracture, MSc thesis, Faculty of Mathematics and Natural Sciences, University of Oslo, Norway.

Hooputra, H., Gese, H., Dell, H., and Werner, H. A. (2004) "Comprehensive failure model for crashworthiness simulation of aluminium extrusions." Int. J. Crashworthiness, 9 (5), 449-64.

Jia, L. and Kuwamura, H. (2014) "Ductile Fracture Simulation of Structural Steels under Monotonic Tension.” J. Struct. Eng., DOI: 10.1061/(ASCE)ST.1943-541X.0000944

Kanvinde, A. M. and Deierlein, G. G. (2006) "The Void Growth Model and the Stress Modified Critical Strain Model to Predict Ductile Fracture in Structural Steels." J. Struct. Eng., 10.1061/(ASCE)0733-9445(2006)132:12(1907).

Kiran, R., and Khandelwal, K. ( 2013) "A micromechanical model for ductile fracture prediction in ASTM A992 steels.” Eng. Frac. Mech., 102, 101-117.

Li, W., Liao, F. Zhou, T., and Askes, H. (2016) "Ductile fracture of Q460 steel: Effects of stress triaxiality and Lode angle.” J. Construct. Steel Res., 123, 1-17.

Li, Y., Luo M., Gerlach, J., and Wierzbicki, T. (2010) "Prediction of shear-induced fracture in sheet metal forming." J. Mat. Proc. Tech., 210, 1858-1869.

Moze, P., Beg, D. and Lopati, J. (2007) “Net cross-section design resistance and local ductility of elements made of high strength steel.” J. Construct. Steel Res., 63, 1431-1441.

Nahshon, K. and Hutchinson, J. W. (2008) "Modification of the Gurson model for shear fracture." Euro. J. Mech. Solids, 27, 1-17. 
265 Rice, J. R. and Tracey, D. M. (1969) "On the ductile enlargement of voids in triaxial stress 266 fields.” J. Mech. Phys. Solids, 17, 201-217.

267 Wen, H. and Mahmoud, H. (2015) "New Model for Ductile Fracture of Metal Alloys. I: 268 Monotonic Loading.” J. Eng. Mech., DOI: 10.1061/(ASCE) EM.1943-7889.0001009.

269 Wilkins, M. L., Streit, R. D. and Reaugh, J. E. (1980) "Cumulative strain- damage model of 270 ductile fracture: simulation and prediction of engineering fracture tests." Research Report 271 No. UCRL-53058, Science Applications, San Leandro, CA.

272 Xue, L. (2008) "Constitutive modeling of void shearing effect in ductile fracture of porous 273 materials.” Eng. Frac. Mech., 75, 3343-3366. 


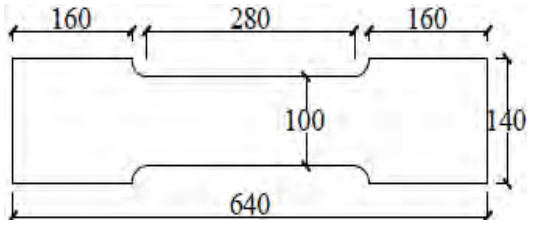

(a)

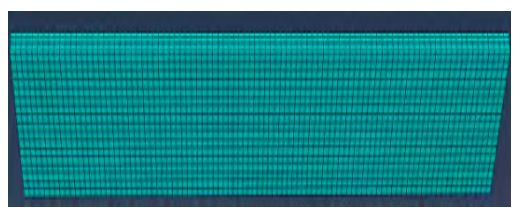

(c)

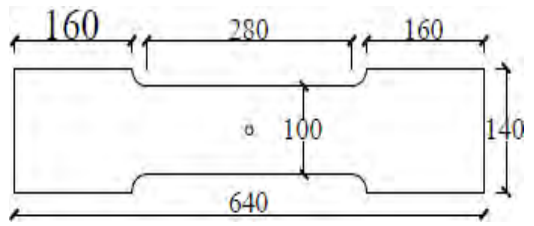

(b)

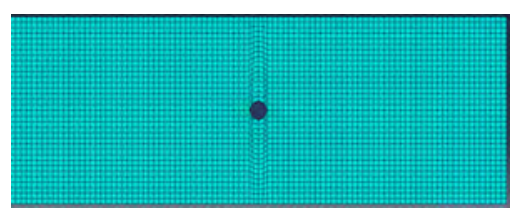

(d)

Figure 1 Test specimens and FE models: (a) Solid tension coupon (H01); (b) Perforated coupon (H04); (c) Solid coupon's FE model; (d) Perforated coupon's FE model. 


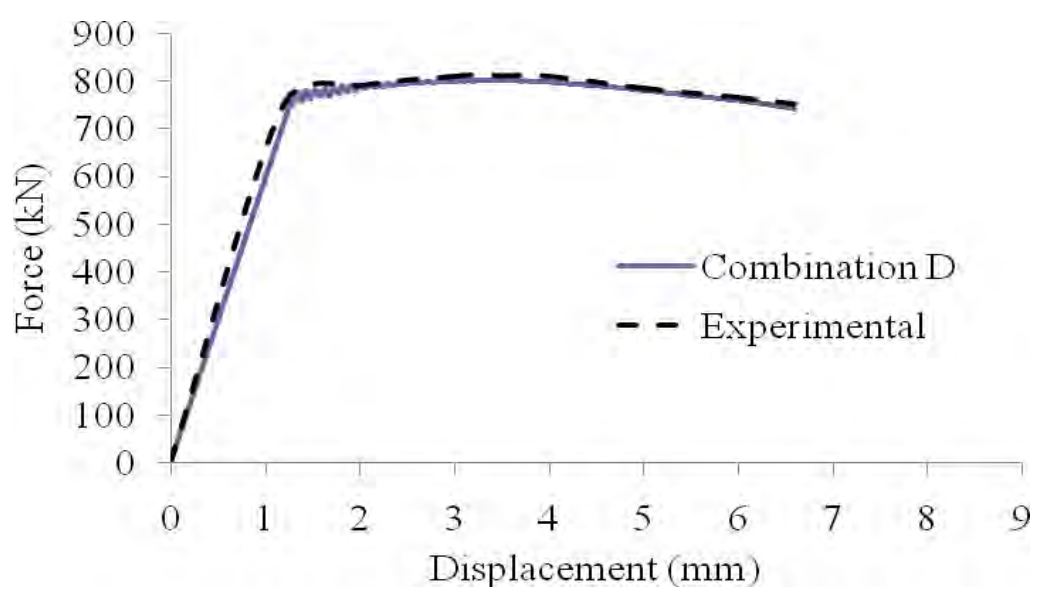

Figure 2 Experimental and analysis results of H04 using parameter combination D 


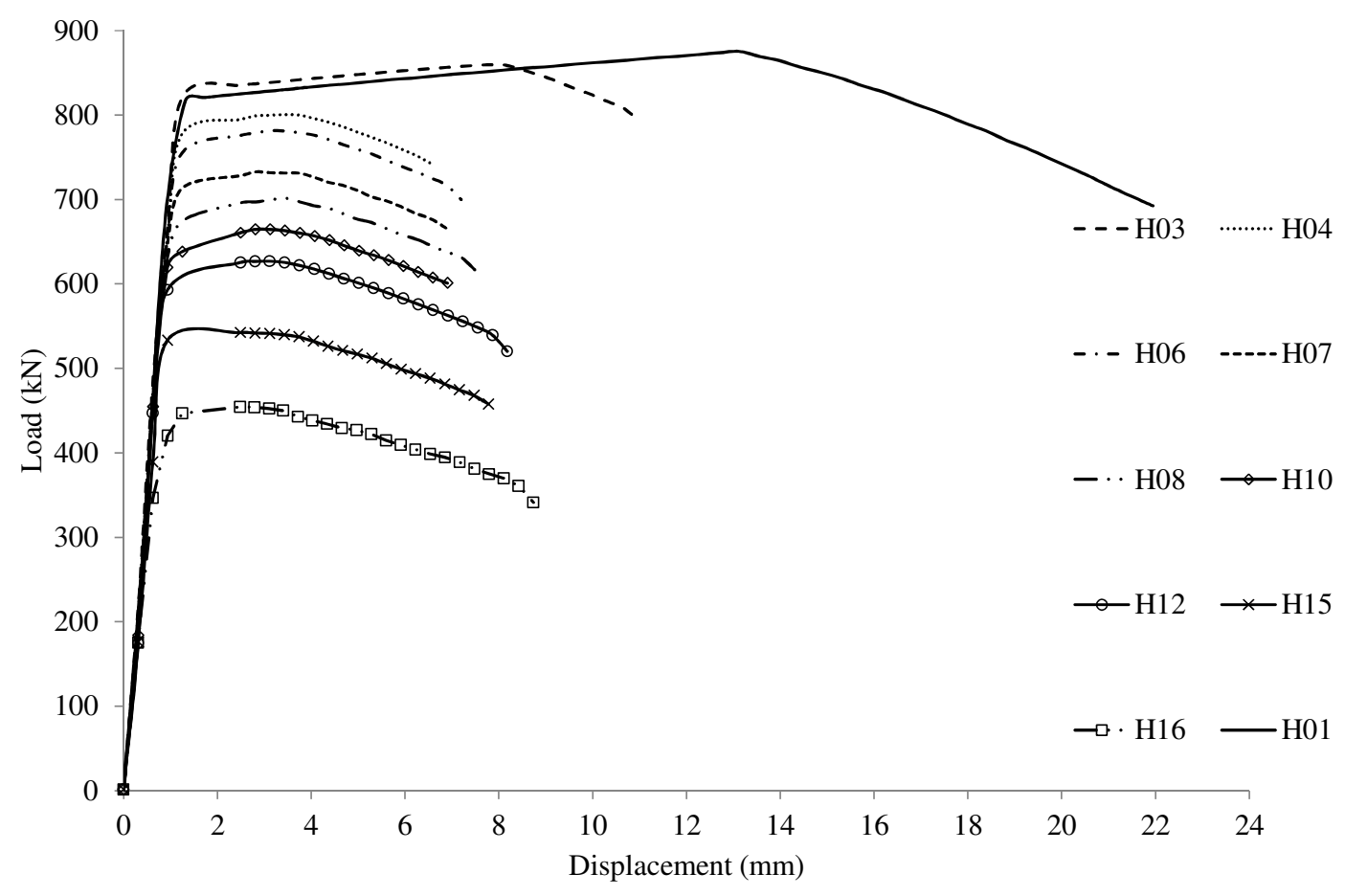

Figure 3 Force-displacement curves for solid coupon (H01) and perforated coupons with varying hole diameters using parameter combination $\mathrm{D}$ 


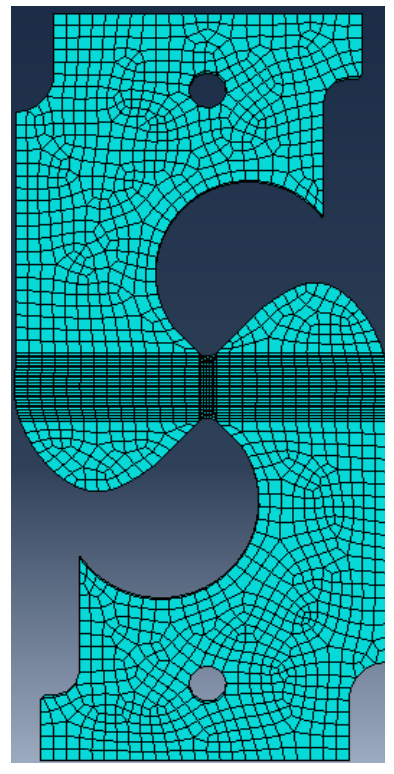

(a)

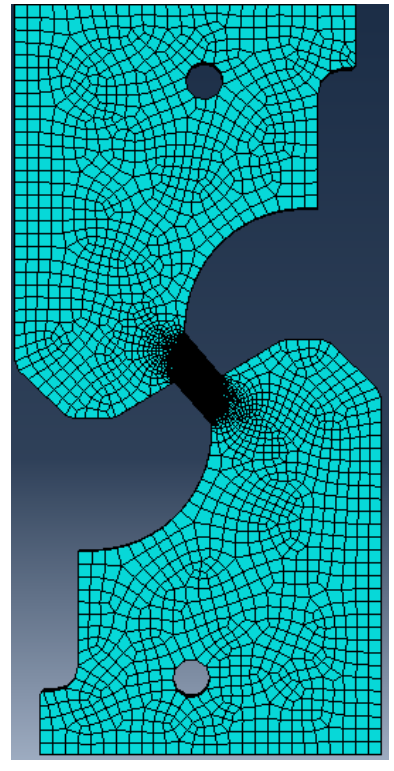

(b)

Figure 4: FE models of: (a) Pure shear specimen; (b) Combined shear and tension specimen 


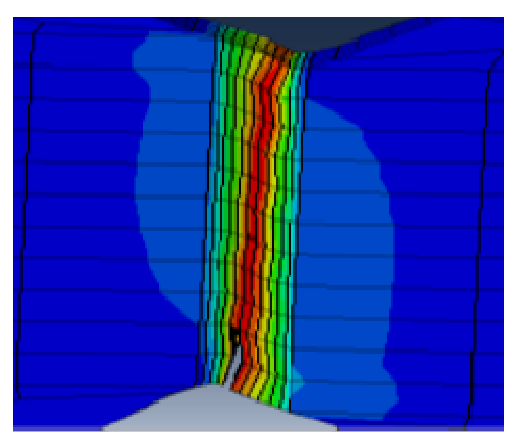

(a)

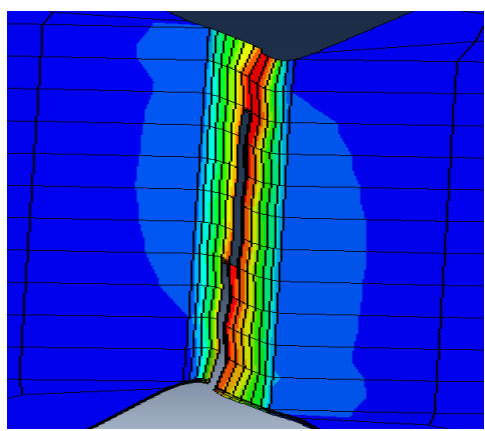

(b)

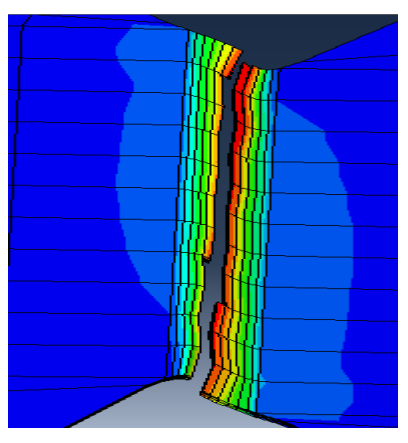

(c)

Figure 5: Predicted fracture processes of the specimen subjected to pure shear: (a) Fracture initiation; (b) Fracture propagation; (c) Complete fracture 

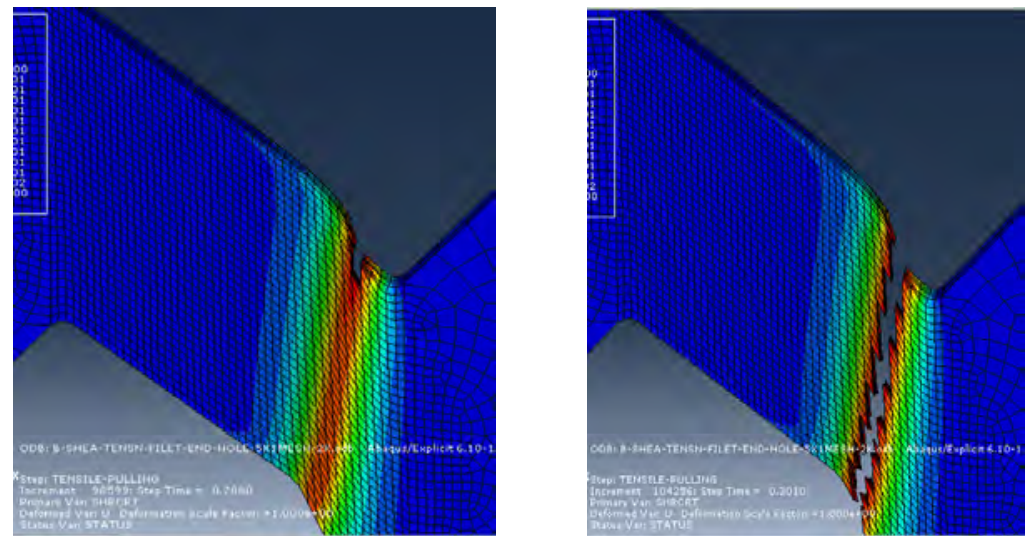

Figure 6: Predicted fracture processes of the specimen subjected to combined shear and tension:

(a) Fracture initiation and propagation; (b) Complete fracture 


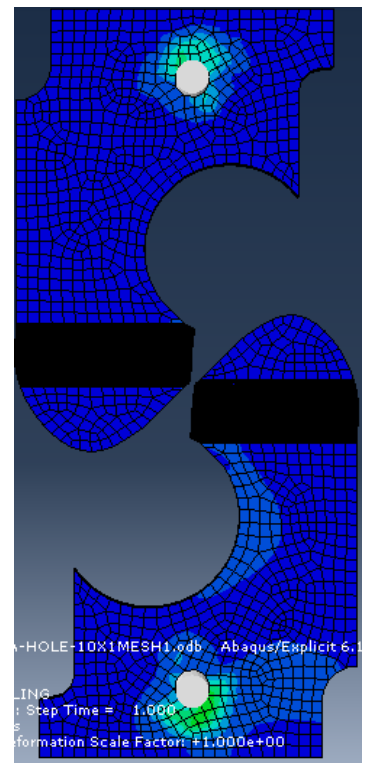

(a)

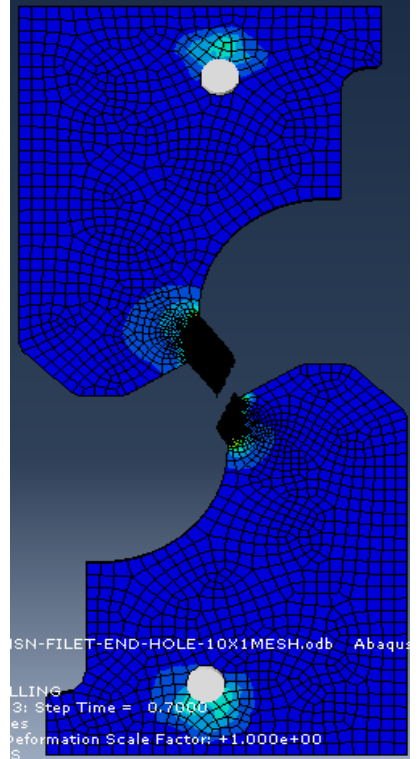

(b)

Figure 7: Predicted fractured shapes: (a) Pure shear specimen; (b) Combined shear and tension specimen 